\title{
Canadian Helicobacter Study Group Consensus Conference on the Approach to Helicobacter pylori Infection in Children and Adolescents
}

\author{
P Sherman MD FRCPC ${ }^{1}$, E Hassall MBChB FRCPC ${ }^{2}$, RH Hunt MD FRCPEd FACG FRCPC ${ }^{3}$, CA Fallone MD FRCPC ${ }^{4}$, \\ S Veldhuyzen van Zanten MD FRCPC ${ }^{5}$, ABR Thomson MD PhD FRCPC FACP FACG ${ }^{6}$, Canadian Helicobacter Study Group*
}

\begin{abstract}
P Sherman, E Hassall, RH Hunt, CA Fallone, S Veldhuyzen van Zanten, ABR Thomson. Canadian Helicobacter Study Group Consensus Conference on the Approach to Helicobacter pylori Infection in Children and Adolescents. Can J Gastroenterol 1999;13(7):553-559. Gastric infection with Helicobacter pylori is common in both children and adults, but children are considerably less susceptible to peptic ulcers and other pathological sequelae. As a result, the risk to benefit ratio of diagnostic studies and therapeutic regimens for $\mathrm{H}$ pylori in adults are likely different from those in pediatric populations. These guidelines for the management of pediatric $H$ pylori infection, developed by the Canadian Helicobacter Study Group, are designed to identify when the diagnosis and treatment of $\mathrm{H}$ pylori may improve patient care. Given the low prevalence of this infection in Canada, it is important to recognize that indiscriminate testing and treatment programs in children are not recommended, and indeed may threaten the optimal care of children. Diagnostic tests should be employed judiciously and be reserved for children who are most likely to derive measurable benefit, such as those likely to have peptic ulcer disease. At this time a test and treat strategy in children cannot be considered prudent, evidence based or cost effective. It is appropriate to limit diagnosis and treatment to children and adolescents in whom $H$ pylori has been identified during endoscopic investigation.
\end{abstract}

Key Words: Canadian Helicobacter Study Group; Helicobacter pylori; Pediatrics
Conférence consensuelle du Groupe canadien pour l'étude d'H. pylori sur l'approche face à l'infection à $H$. pylori chez les enfants et les adolescents

\begin{abstract}
RÉSUMÉ : L'infection gastrique à Helicobacter pylori est fréquente chez les enfants et chez les adultes, mais les enfants sont beaucoup moins susceptibles de souffrir d'ulcères gastro-duodénaux ou d'autres séquelles pathologiques. Par conséquent, le rapport risques-avantages des analyses diagnostiques et des schémas thérapeutiques appliqués à $H$. pylori chez les adultes risque fort d'être différent de ce qu'il est chez les populations pédiatriques. Ces directives pour un traitement de l'infection à $H$. pylori chez l'enfant mises au point par le Groupe canadien pour l'étude d'H. pylori, sont conçues pour identifier à quel moment le diagnostic et le traitement d'H. pylori peuvent améliorer les soins aux patients. Compte tenu de la prévalence faible de cette infection au Canada, à l'heure actuelle, il n'est par recommandé d'appliquer d'emblée des programmes diagnostiques et thérapeutiques chez les enfants, car en fait ils pourraient même nuire aux soins optimum qui leur sont prodigués. Les tests diagnostiques doivent être utilisés avec circonspection et réservés aux enfants qui sont les plus susceptibles d'en tirer un avantage mesurable, par exemple, ceux qui souffrent peut-être d'une maladie ulcéreuse. À l'heure actuelle, on peut affirmer qu'il ne serait pas prudent de recourir à des stratégies diagnostiques et thérapeutiques chez les enfants, qu'elles ne se fondent pas sur des preuves et ne seraient pas rentables. Il convient de réserver les épreuves diagnostiques et les traitements aux enfants et adolescents chez qui $H$. pylori a été identifié lors d'une épreuve endoscopique.
\end{abstract}

*Please see appendix for the names of the Canadian Helicobacter Study Group members who are co-authors of the present article

${ }^{1}$ Division of Gastroenterology and Nutrition, Department of Pediatrics, University of Toronto, Toronto, Ontario; ${ }^{2}$ Division of Gastroenterology, Department of Pediatrics, BC's Children's Hospital, Vancouver, British Columbia; ${ }^{3}$ Division of Gastroenterology, Department of Medicine, McMaster University, Hamilton, Ontario; ${ }^{4}$ Division of Gastroenterology, Department of Medicine, McGill University, Montreal, Quebec;

${ }^{5}$ Division of Gastroenterology, Department of Medicine, Dalhousie University, Halifax, Nova Scotia; ${ }^{6}$ Division of Gastroenterology, Department of Medicine, University of Alberta, Edmonton, Alberta

Correspondence and reprints: Dr P Sherman, Division of Gastroenterology and Nutrition, Room 8411, The Hospital for Sick Children, 555 University Avenue, Toronto, Ontario M5G 1X8. Telephone 416-813-7734, fax 416-813-6531, e-mail sherman@sickkids.on.ca 
$\mathrm{H}$ elicobacter pylori is a common gastrointestinal pathogen worldwide. Canadian and other treatment guidelines recommend the eradication of $H$ pylori in infected adults, particularly in those with peptic ulcer disease $(1-5)$. As noted in the first (1) and recently updated (2) Canadian $H$ pylori consensus documents, there are several reasons why guidelines for adults with infection are not necessarily applicable to children. Most important, the frequency of $\mathrm{H} p y$ lori-related diseases is much lower in children, thereby profoundly altering the risks, benefits and costs of treatment and investigation.

Rational and appropriate guidelines for diagnosing and treating $H$ pylori infection in children are needed (6). This need stimulated the convening of the Canadian Helicobacter Consensus Conference on Pediatric Issues, held November 20 to 22, 1998 in Victoria, British Columbia. The goal of the conference was to evaluate the scientific evidence regarding the epidemiology, pathophysiology and management of $H$ pylori infection in children.

Although $\mathrm{H}$ pylori is an established pathogen for both duodenal ulcer and gastric ulcer disease, the great majority of infected individuals harbour this organism for life, with no apparent adverse health consequences. It is also important to recognize that inappropriate diagnostic testing and/or treatment may be prejudicial to patient care $(7,8)$. Therefore, these guidelines were produced to indicate which children may benefit from testing for the presence of $H$ pylori infection, which tests may be useful, and which children and adolescents may benefit from treatment.

These guidelines represent one of the first collaborative efforts to define appropriate management of $H$ pylori infection in children and adolescents, based on scientific evidence. A broad representation of disciplines participated in the development of the consensus guidelines, including pediatric and adult gastroenterologists, infectious disease specialists, medical microbiologists, family physicians, pharmacists, pathologists and basic science researchers. Also present were participants from Europe, the United States, the pharmaceutical industry and the Canadian government. The conference was sponsored by the Canadian Association of Gastroenterology, the Canadian Digestive Disease Foundation, and the Canadian Society for Clinical Investigation. Major financial support for the Conference was provided through equal unrestricted educational grants from Abbott Laboratories Ltd (Saint-Laurent, Quebec), Astra Pharma Inc (Mississauga, Ontario), Axcan Pharma Inc (Mont StHilaire, Quebec), Byk Canada Inc/Solvay Pharma Inc (Scarborough, Ontario) and Glaxo Wellcome Inc (Mississauga, Ontario).

\section{BACKGROUND}

H pylori is a significant etiological factor in diseases of the upper gastrointestinal tract. The organism was first isolated from the human stomach less than 20 years ago. In Canada, the prevalence of infection varies by region and ethnic subgroup, ranging from $20 \%$ to $40 \%$ in some adult populations (9). In contrast, prevalence rates of $H$ pylori infection are higher in developing countries, where the prevalence rate in adults reaches as high as $80 \%(10)$. Importantly, in developing countries the acquisition rates are higher and occur at a much younger age. Many children in the developing world, therefore, harbour the organism for most of their lives.

Once acquired, infection with $H$ pylori persists indefinitely in most patients. However, even though infected individuals develop a chronic active gastritis of variable severity, the great majority do not develop a clinically significant disease. While the local inflammatory response to infection is the likely precipitating event for complications, the reasons why only $10 \%$ to $20 \%$ of those infected develop clinical disease are not well understood. Individual differences in immune function, acid secretion and other host responses to infection may be important, but there is also evidence that differences in virulence among strains of $H$ pylori may affect clinical risk (11-13).

Chronicity of infection may be another risk factor for clinical sequelae. Although epidemiological studies suggest that the majority of infected individuals acquire $H$ pylori infection in childhood, peptic ulcers and other associated diseases are uncommon in the pediatric population. It is not clear whether susceptibility to clinical diseases evolves slowly, delaying the clinical risks of $H$ pylori infection to adulthood, or whether children benefit from an unknown protective host factor.

The evidence that children are more vulnerable than adults to infection with $\mathrm{H}$ pylori is derived from seroconversion rates; rates range from $0.3 \%$ to $1.1 \%$ per year in adults but are two to three times higher in children (14). Studies from developing countries suggest that most children acquire $H$ pylori infection before the age of five years (14). The inverse relationship between socioeconomic status and the prevalence of infection suggests that sanitation and crowding are important variables affecting transmission $(15,16)$. Clustering of infection has been observed within families and in daycare centres (17). The most likely routes of transmission appear to be gastro-oral (via vomitus) or fecal-oral.

In adults, $H$ pylori infection is considered to be the cause of about $90 \%$ of duodenal ulcers and $70 \%$ of gastric ulcers not associated with the use of nonsteroidal anti-inflammatory drugs. However, even in $H$ pylori-infected children, peptic ulcer is uncommon, particularly before adolescence $(18,19)$. Although $H$ pylori infection is considered a cause of peptic ulcers in children, the proportion of children presenting with ulcer-like symptoms who prove to have significant mucosal erosions or ulceration is small compared with that of the adult population. Furthermore, it is difficult to know what constitutes 'ulcer-like symptoms' in children. However, cure of the $H$ pylori infection does lead to cure of $H$ pylori-associated ulcers in children (20).

Mucosa-associated lymphoid tissue (MALT) gastric lymphomas are exceedingly rare in children. Although more than $90 \%$ of adults who develop gastric MALT lymphomas are infected with H pylori, fewer than five cases have been reported worldwide in children $(21,22)$. It is assumed that eradication produces partial or complete regression of 
MALT lymphomas in children, as it does in adults. Unfortunately, definitive conclusions are limited, given insufficient published data from clinical experience or trials. Close follow-up of children with MALT lymphomas is recommended, as with adults.

The relationship between $H$ pylori infection and dyspepsia remains controversial in both adults and children. In adults, eradication of $H$ pylori has not been associated consistently with symptomatic relief in either case-control or short term treatment trials performed in adults. Less than half of the $H$ pylori eradication trials in children with recurrent abdominal pain demonstrate successful symptomatic benefit with infection eradication (23). In addition, relatively small sample sizes and very short durations of follow-up prevent definitive conclusions from being drawn.

$\mathrm{H}$ pylori has been classified as a group I carcinogen by the World Health Organization on the basis of epidemiological evidence indicating a close association with an increased risk of gastric cancer. However, gastric adenocarcinoma appears to be multifactorial in etiology, with genetic and dietary factors playing a significant role. For example, some populations with a high prevalence of $\mathrm{H}$ pylori infection have low rates of gastric cancer (24). Furthermore, it is not yet clear whether eradication of infection can reduce cancer risk. Gastric adenocarcinomas are rare in children, and the presumed relationship between $H$ pylori and long term cancer risk may be relevant to pediatric care if eradication at an early age is shown to significantly reduce risk in adulthood.

\section{PEDIATRIC IMMUNOPATHOLOGY AND H PYLORI}

There is no convincing evidence to date that the host response to $H$ pylori infection differs significantly between adults and children $(25,26)$. However, the relative infrequency of clinical diseases from $\mathrm{H}$ pylori infection among children is a basis for suggesting that the pathology of infection may not be the same as in adults. The purported differences are of potential interest in understanding why $\mathrm{H}$ pylori produces clinically relevant disease in only a minority of individuals, even as adults. One potential difference between children and adults is that the inflammatory response to infection may be more modest in a developing immune system than in a mature immune system. Less inflammation may reduce the risk of disruption to the mucosa of the gastric epithelium and modify associated physiological changes such as altered acid secretion, favouring survival of $\mathrm{H}$ pylori.

In young children, relative protection from the pathogenic effects of $H$ pylori infection may be derived from a predisposition to a T helper cell type-2 (Th2) rather than a T helper cell type 1 (Th1) immune response. Relative to the Th1 response, which is associated with release of proinflammatory cytokines, the Th2 response is dominated by antiinflammatory effects. These varying immune responses of the host may make the gastrointestinal tract less accommodating to $H$ pylori survival (27). This response may even lead to spontaneous clearance of $H$ pylori in young children, a rare event in adults. Age-specific studies are needed to explore this hypothesis further.

No definitive histological studies have compared the inflammatory response between adults and children. Initial reports that histological changes, such as atrophic gastritis, are less common in children provide a preliminary basis on which to predict differences $(28,29)$. In future studies designed to identify why $H$ pylori infection may pose fewer clinical risks in children than in adults, it will be important to compare the risk of structural damage by age in the context of inflammatory cell types and the distribution of inflammation in the stomach and duodenum.

There is evidence suggesting that some strains of $H$ pylori are more virulent than others $(11,12)$. Several characteristics of the organism, known as virulence factors, have been associated with an increased severity of gastritis, accelerated apoptosis, and more rapid turnover of gastric epithelial cells in both adults and children (30). However, there is no evidence that such virulence factors affect children and adults differently.

Differentiating the immunopathology of $H$ pylori infection by age group is a critical direction for future research. Differences in susceptibility and immune response may have relevance to public health initiatives to thwart the transmission of $\mathrm{H}$ pylori, as well as to vaccine development. Not enough is known about whether endogenous host defences, such as immunoglobulins passively transferred in breast milk, affect $H$ pylori colonization. It is also unknown whether age-specific differences in immune function are important to sustain infection or clinically significant sequelae. In addition to modifying the risks of $\mathrm{H}$ pylori infection in children and adolescents, more information in these areas may lead to new strategies for preventing disease outcomes in adults.

\section{SIGNIFICANCE OF PEDIATRIC GUIDELINES}

H pylori is a pathogen in children, as it is in adults. Although clinical expression of diseases resulting from this infection is rare in the pediatric population, the organism invariably produces a chronic active gastritis, and this may be associated with a significantly increased risk of gastrointestinal disease if allowed to persist into adult life. In adults, the lifetime risk of peptic ulcer is approximately twice as high in infected as in noninfected individuals $(31,32)$, and in certain geographic areas the relative risk of developing gastric adenocarcinoma is increased by a factor of 2.0 to $6.0(33-36)$.

Only a small proportion of children develop symptoms and clinically relevant upper gastrointestinal disease, and few of these symptoms are thought to be related to $H$ pylori. Even for children with proven $H$ pylori infection, there is insufficient objective evidence to indicate that eradication of the infection is beneficial. As a result, indiscriminate testing and treatment programs in children are not recommended. Diagnostic tests should be employed judiciously and be reserved for children who are most likely to derive measurable benefit, such as those who may reasonably be suspected of having peptic ulcer disease.

There is considerable concern that diagnostic tests and 
treatments for $H$ pylori infection will be used in excess of their established benefit in the pediatric population. In children, the etiology of gastrointestinal symptoms is often elusive, even after a careful history and detailed physical examination are conducted. With growing awareness among the general population about the potential for $\mathrm{H}$ pylori to cause gastrointestinal symptoms in adults, testing and treating for $\mathrm{H}$ pylori infection may be viewed as an attractive step toward eliminating one possible etiological factor. However, it is important to recognize that $\mathrm{H}$ pylori-related disease in children is rare, while abdominal symptoms are a very common reason for children to present to physicians.

Diagnostic tests have overt, up-front costs, and expense often is cited as a reason not to perform a test. Conversely, low cost is sometimes cited as a reason to perform a test. However, consideration of only the costs billed to the medical system or patient is often misleading. For example, there are significant financial and social costs associated with failure to reach an accurate diagnosis; the costs of a missed or inaccurate diagnosis include the costs of more tests, more doctor visits, inappropriate treatment, and missed school or work. An expensive test that is definitive may result in overall cost savings (37). The cost-benefit relationship of testing the large numbers of children who present with abdominal pain for a lower prevalence of peptic ulcer disease is likely to be higher, case by case, than in adults. In other words, there is likely a higher cost of finding the relatively few peptic ulcers in children by using nondefinitive testing, than there is in adults.

Although eradication of infection is appropriate in children and adolescents with proven $\mathrm{H}$ pylori-associated duodenal or gastric ulcer disease, there is no convincing evidence that cure benefits the much larger proportion of infected patients with gastritis alone. A test and treat strategy early in the course of evaluation of upper abdominal symptoms exposes the patient to the potential risks of treatment and may lead to antibiotic resistance (in treatment failures) with only a modest hope of benefit. Therefore, this strategy cannot be considered prudent, evidence based or cost effective. It is important to stress that $H$ pylori should be considered in the differential diagnosis of the cause of the child's symptoms only after other, more common, etiological factors are considered. Therefore, testing for $\mathrm{H}$ pylori infection should not be considered part of the initial investigative strategy.

The guidelines that follow are designed to provide a practical interpretation of scientific evidence. Although the link between $H$ pylori infection and peptic ulcer disease is a major clinical advance in the management of peptic ulcer disease, it is important to apply treatment where there is established benefit. There is much yet to be learned about the risks posed by $H$ pylori infection. However, the infrequency with which this organism produces clinically apparent disease in children indicates that a conservative approach is most appropriate.

\section{DIAGNOSTIC RECOMMENDATIONS}

The symptoms of $H$ pylori-related disease and, specifically, peptic ulcer in children are nonspecific and can include epigastric pain especially after meals, night-time waking, unex- plained nausea or recurrent vomiting, unexplained anorexia, hematemesis and iron deficiency anemia. The predictive value of any of these symptoms for an $\mathrm{H}$ pylori-related disease is unknown but is considered to be low. There are no data on symptoms in children under the age of five years. Therefore, $H$ pylori testing should not be a first step in children who present with persistent abdominal complaints or unexplained nausea or vomiting.

1) The goal of diagnostic interventions should be to determine the cause of presenting gastrointestinal symptoms, rather than the presence of $\mathrm{H}$ pylori infection.

Comment: Testing for $\mathrm{H}$ pylori infection is recommended only if there is a high probability that the symptoms are due to peptic ulcer disease. If a peptic ulcer is identified during investigation by endoscopy (or upper gastrointestinal barium studies), it is reasonable to test for $\mathrm{H}$ pylori. It is important to recognize that barium studies have a high false positive rate for peptic ulcer disease in children.

2) Testing for $\mathrm{H}$ pylori infection is appropriate only when treatment is planned if the test is positive.

Comment: Even though health benefits from eradication cannot be assured in any given individual, it is recommended that an infection known to be present be treated. The controversial nature of this issue should be discussed, and treatment be given with parental informed consent.

3) Antibody tests for $\mathrm{H}$ pylori infection using whole blood, serum or saliva are not recommended.

Comment: Because of the low prevalence of $\mathrm{H}$ pylori-related diseases in children, the low specificity and sensitivity of antibody tests for whole blood, serum and saliva reduce their value for establishing the presence of a current $H$ pylori infection. In addition, antibody levels may remain elevated for years after eradication or resolution of the infection. Therefore, a positive test does not necessarily mean that infection is present at the time of testing.

4) Upper gastrointestinal endoscopy with multiple biopsies is the optimal approach to the investigation of the pediatric patient with chronic upper abdominal symptoms or suspected peptic ulcer disease.

Comment: The differential diagnosis of abdominal pain in a child may include esophagitis due to gastroesophageal reflux or other causes, gastritis or gastropathy from a variety of causes, and peptic ulcer disease, either $\mathrm{H}$ pylori-associated or not (38). Endoscopy with biopsies provides the most accurate approach for definitive diagnosis of upper gastrointestinal mucosal diseases. Endoscopy is the only acceptable diagnostic test in children with upper gastrointestinal bleeding, recurrent vomiting or persistent undiagnosed abdominal pain.

5) ${ }^{13} \mathrm{C}$ - (or ${ }^{14} \mathrm{C}$-) urea breath tests are not an appropriate alternative to upper endoscopy for primary diagnosis of $H$ pylori infection in children. Urea breath tests are more appropriate than repeat endoscopy to confirm successful eradication of $\mathrm{H}$ pylori.

Comment: The sensitivity and specificity of labelled urea breath tests, which are noninvasive, are close to those of endoscopic biopsies for the presence of $H$ pylori infection (39). 
Breath testing is also less expensive than endoscopy. However, in most clinical scenarios in pediatrics, the diagnosis of the cause of the patient's symptoms is a more useful goal rather than simply determining whether $H$ pylori infection is present. For instance, a positive breath test does not confirm or exclude the presence of an ulcer, other gastritides, gastropathies or esophageal disease. Similarly, this indirect testing cannot determine gastroduodenal pathology or rule out alternative diagnoses in the event of a negative result. However, urea breath tests, performed four to six weeks after the end of treatment, do offer acceptable accuracy for evaluating the success of an eradication regimen. These tests are warranted in children treated for $\mathrm{H}$ pylori-related ulcers or those suspected of poor compliance. Endoscopy after treatment is only appropriate if there are additional indications for this procedure, such as to confirm ulcer healing in a child with a history of bleeding or perforation.

6) H pylori cultures are not routinely required for diagnosis but may be warranted after failure of initial treatment or as part of a surveillance program for antibiotic resistance.

Comment: Cultures do not substantially improve diagnostic accuracy for $\mathrm{H}$ pylori infection over that achieved with endoscopy or urea breath tests. However, culture of gastric biopsies does permit antibiotic sensitivity testing in the event of treatment failure to detect resistant organisms and guide future treatment.

7) Children previously suspected of having a peptic ulcer by barium studies should be examined by endoscopy if their symptoms recur.

Comment: Barium studies are not reliable for evaluating suspected lesions of the upper gastrointestinal tract in the pediatric population. In children whose peptic ulcer was previously diagnosed by an upper gastrointestinal series, endoscopy with biopsies should be performed to confirm the presence of an ulcer and to diagnose $H$ pylori infection. An alternative is to consider doing a ${ }^{13} \mathrm{C}$-urea breath test if the barium study is considered diagnostic.

8) Screening for $\mathrm{H}$ pylori infection in asymptomatic individuals is not warranted.

Comment: Screening for $\mathrm{H}$ pylori infection is costly, and there are no established public health benefits in asymptomatic children, adolescents or adults.

9) Family members of previously infected patients who have benefited from $\mathrm{H}$ pylori eradication can be considered for testing and treatment.

Comment: It is rational, although totally unproven, that testing and treating family members for $\mathrm{H}$ pylori infection may be justified by a possible reduced risk of reinfection in a child who has benefited from eradication therapy. However, the projected benefits should be weighed against the risks and costs of this strategy.

\section{TREATMENT RECOMMENDATIONS}

There are several drug regimens that can eradicate $H$ pylori infection in at least $80 \%$ of adults, as determined by intention-to-treat analyses of randomized, controlled clini- cal trials (1,39-41). However, the regimens have not yet been tested in children. Rather, most pediatric treatment trials have been small and uncontrolled. These trials provide a preliminary basis for inferring that regimens that are effective in adults will provide similar efficacy in children. However, there are important unanswered questions about the risk of adverse events, and how or whether doses should be modified by chronological age or body weight.

Because of the absence of data, the principles of evidence-based medicine could not be employed in developing the following recommendations. Rather, data from studies in adults were extrapolated, with the understanding that modifications may be necessary once appropriate randomized trials are conducted in the pediatric age groups.

Empirical treatment of gastrointestinal symptoms through eradication of $\mathrm{H}$ pylori infection is not recommended in either children or adults. Rather, treatment should be considered only after $H$ pylori infection has been diagnosed by an appropriate test for an appropriate indication. However, treatment should be offered to any child with a proven current $H$ pylori infection, regardless of why the infection was identified. If a treatment recommendation is refused, a full discussion should include an acknowledgement that eradication may not eliminate or improve symptoms in patients without ulcers, but that an infected individual faces a $10 \%$ to $15 \%$ lifetime risk of peptic ulcer disease and, depending on the ethnic group and family history of the child, an increased risk of gastric cancer.

1) The first line treatment for $H$ pylori infection is a twice-daily, triple-drug regimen comprising a proton pump inhibitor (PPI) plus two antibiotics. In combination with a PPI, the acceptable antibiotic combinations are clarithromycin plus amoxicillin or clarithromycin plus metronidazole. The optimal period of treatment is seven to 14 days.

Comment: In adults, seven-day treatment regimens with twice-daily, triple drug therapies are effective and well tolerated (although 10- to 14-day regimens are recommended in the United States). In children, a longer period of treatment may increase the assurance of efficacy, but the relationship between length of treatment and efficacy has not yet been studied.

At this time, there do not appear to be major differences in efficacy among the various PPIs for healing peptic ulcers. Dosing regimens, treatment efficacy and safety issues have been addressed for omeprazole use in children with erosive esophagitis (42).

2) Triple therapy with PPI plus clarithromycin and amoxicillin may provide practical advantages over PPI plus clarithromycin and metronidazole in children.

Comment: Although both regimens offer comparable efficacy in adults, clarithromycin and amoxicillin are available in liquid form, increasing the convenience and, potentially, compliance in children. Metronidazole has an unpleasant taste that may reduce compliance. Tetracycline should not be used to treat $H$ pylori infection in children under 12 years of age because of its effects on the enamel of developing teeth. 


\section{FUTURE DIRECTIONS}

It is important to recognize that the long term risks of persistent $H$ pylori infection and chronic active gastritis remain incompletely understood, both in children and in adults. If additional benefits from eradication are identified, it will be essential to adjust management recommendations accordingly. Of particular interest is the potential causal relationship between $H$ pylori-induced gastritis and dyspepsia. Several trials have evaluated this in adults and children, but the results are inconsistent. One possible explanation for the apparent initial benefit and later recurrence of dyspeptic symptoms following therapy seen in some studies is an early placebo response to endoscopy or treatment itself. In instances where dyspeptic symptoms do not resolve, one possible explanation is that symptoms resolve slowly, and that long term follow-up may be required to document improvements after gastritis resolves fully. If eradication is associated with significant improvement in symptoms, the risk to benefit ratio will be altered. However, in the pediatric population, symptoms are likely to be less specific than in adults. Indeed, it is well recognized that symptom-based diagnoses are unreliable. Thus, for children, a test and treat strategy is less likely to be useful.

Public health measures likely to reduce the transmission of $H$ pylori infection deserve greater scrutiny. No precautions, other than sensible hygiene, are recommended for reducing the risk of new infections. In children who may be more susceptible than adults to infection with $H$ pylori, opportunities to reduce the risk of transmission may exist in high risk environments.

Less costly, safer and more convenient methods of treatment may exert a strong influence on the indications for the diagnosis and treatment of $H$ pylori infection. Vaccines that are under development have particular potential for altering the assumptions on which current recommendations are based. Although some patients appear to tolerate persistent

\section{REFERENCES}

1. Hunt RH, Thomson ABR, Consensus Conference participants. Canadian Helicobacter pylori Consensus Conference. Can J Gastroenterol 1998;12:31-41.

2. Hunt RH, Fallone CA, Thomson ABR, Canadian Helicobacter Study Group. Canadian Helicobacter pylori Consensus Conference Update: Infections in adults. Can J Gastroenterol 1999;13:213-7.

3. Current European concepts in the management of Helicobacter pylori infection. The Maastricht Consensus Report. European Helicobacter Pylori Study Group. Gut 1997;41:8-13.

4. The report of the Digestive Health Initiative SM $_{\text {International Update }}$ Conference on Helicobacter pylori. Gastroenterology 1997;113 (6 Suppl):S4-8.

5. Lam SK, Talley NJ. Report of the 1997 Asia Pacific Consensus Conference on the management of Helicobacter pylori infection. J Gastroenterol Hepatol 1998;13:1-12.

6. Gold BD, Robie-Suh K, Sherman PM. Pediatric Issues Workshop summary. Helicobacter 1998;3:305-9.

7. Labenz J, Blum AL, Bayerdorffer E, Meining A, Stolte M, Borsch G. Curing Helicobacter pylori infection in patients with duodenal ulcer may provoke reflux esophagitis. Gastroenterology 1997;112:1442-7.

8. Hawkey CJ, Tulassay Z, Szczepanski L, et al. Randomised controlled trial of Helicobacter pylori eradication in patients on non-steroidal anti-inflammatory drugs: HELP NSAIDs study. Helicobacter Eradication for Lesion Prevention. Lancet 1998;352:1016-21.

9. Veldhuyzen van Zanten SJO, Pollack PT, Best LM, Bezanson GS, Marrie T. Increasing prevalence of Helicobacter pylori infection with age:
H pylori infection with no known health consequences, safe and inexpensive interventions will encourage more aggressive eradication strategies, including population-based approaches.

Studies of $\mathrm{H}$ pylori infection in children have the potential to provide important insight about the risks of this organism to the human host. For example, a correlation between age and specific features of the immune response, epithelial cell turnover and immune cell recruitment, may lead to new understanding about the importance of the host response to clinical risks. The freedom from clinical sequelae seen in the pediatric population, in comparison with the adult population, may also provide opportunities to determine pathogenic mechanisms.

Progress in the understanding of this infection and the approach to treatment since $H$ pylori was first isolated has been impressive, but new directions in $H$ pylori research remain valid. It is essential to recognize that this infection remains an evolving area of biomedical research.

\section{SUMMARY}

$\mathrm{H}$ pylori is a significant gastrointestinal pathogen in adults but in Canada is an uncommon cause of clinically significant disease in childhood. Therefore, the indications for diagnosis and treatment in these two groups are not interchangeable. Although it is evident that there are certain pediatric patients in whom there is significant clinical benefit from treatment, this is not the case for the majority of infected children. Therefore, it is appropriate to limit diagnosis and treatment to individuals in whom $H$ pylori infection has been identified during endoscopic investigation.

ACKNOWLEDGEMENTS: This symposium was sponsored equally by unrestricted educational grants from Abbott Laboratories Ltd, Astra Pharma Inc, Axcan Pharma Inc, Byk/Solvay Pharma Inc and Glaxo Wellcome Inc. continuous risk of infection in adults rather than cohort effect. J Infect Dis 1994;169:434-7.

10. Megraud F, Brassens-Rabbe MP, Denis F, Belbouri A, Hoa DQ Seroepidemiology of Campylobacter pylori infection in various populations. J Clin Microbiol 1989;27:1870-3.

11. Fallone CA, Barkun AN, Gottke MU, Beech RN. A review of the possible bacterial determinants of clinical outcome in Helicobacter pylori infection. Can J Microbiol 1998;44:201-10.

12. Blaser MJ. Helicobacter pylori phenotypes associated with peptic ulceration. Scand J Gastroenterol 1994;29(Suppl 205):1-5.

13. Graham DY, Malaty HM, Go MF. Are there susceptible hosts to Helicobacter pylori infection? Scand J Gastroenterol 1994;29 (Suppl 205):6-10.

14. Linkvist P, Asrat D, Nilsson I, et al. Age at acquisition of Helicobacter pylori infection: Comparison of a high and a low prevalence country. Scand J Infect Dis 1996;28:181-4.

15. Graham DY, Malaty HM, Evans DG, Evans DJ, Klein PD, Adam E. Epidemiology of Helicobacter pylori in an asymptomatic population in the United States. Gastroenterology 1991;100:1495-501.

16. Malaty HM, Graham DY. Importance of childhood socioeconomic status on the current prevalence of Helicobacter pylori infection. Gut 1994;35:742-5.

17. Drumm B, Perez-Perez GI, Blaser MJ, Sherman PM. Intrafamilial clustering of Helicobacter pylori infection. N Engl J Med 1990;322:359-63.

18. Brenner H, Rothenbacher D, Bode G, Adler G. Parental history 
of gastric or duodenal ulcer and prevalence of Helicobacter pylori infection in preschool children: population based study. BMJ 1998;316:665.

19. Hassall E, Dimmick JE. Unique features of $H$. pylori disease in children. Dig Dis Sci 1991;36:417-23.

20. Dohil R, Israel DM, Hassall E. Effective 2-week therapy for Helicobacter pylori disease in children. Am J Gastroenterol 1996;92:244-7.

21. Horstmann M, Erttmann R, Winkler K. Relapse of MALT lymphoma associated with Helicobacter pylori after antibiotic treatment. Lancet 1994;343:1098-9.

22. Blecker U, McKeithan TW, Hart J, Kirschner BS. Resolution of Helicobacter pylori-associated gastric lymphoproliferative disease in a child. Gastroenterology 1995;109:973-7.

23. Macarthur C, Saunders N, Feldman W. Helicobacter pylori, gastroduodenal disease, and recurrent abdominal pain in children. JAMA 1995;273:729-34.

24. Hu PJ, Li YY, Lin HL, et al. Gastric atrophy and regional variation in upper gastrointestinal disease. Am J Gastroenterol 1995;90:1102-6.

25. Queiroz DMM, Rocha GA, Mendes EN, et al. Differences in distribution and severity of Helicobacter pylori gastritis in children and adults with duodenal ulcer disease. J Pediatr Gastroenterol Nutr 1991;12:178-81.

26. Jones NL, Sherman P, Croitoru K. Immunobiology of the stomach: The Helicobacter model. Can J Allergy Clin Immunol 1998;3:58-63.

27. Bamford KB, Fan X, Crowe SE, et al. Lymphocytes in the human gastric mucosa during Helicobacter pylori have a T helper cell 1 phenotype. Gastroenterology 1998;114:482-92.

28. Mitchell HM, Bohane TD, Tobias V, et al. Helicobacter pylori infection in children: potential clues to pathogenesis. J Pediatr Gastroenterol Nutr 1993;16:120-5.

29. Quieroz DMM, Moura SB, Mendes EN, Rocha GA, Barbosa AJA, deCarvalho AST. Effect of Helicobacter pylori eradication on G-cell and D-cell density in children. Lancet 1994;343:1191-3.

30. Jones NL, Shannon PT, Cutz E, Yeger H, Sherman PM. Increase in proliferation and apoptosis of gastric epithelial cells early in the natural history of Helicobacter pylori infection. Am J Pathol 1997;151:1695-703.

31. Cullen DJE, Collins BJ, Christiansen KJ, Epis J, Warren JR,
Cullen KJ. Long term risk of peptic ulcer disease in people with Helicobacter pylori infection - a community based study. Gastroenterology 1993;104:A60. (Abst)

32. Sipponen P, Varis K, Fraki O, Korri UM, Seppala K, Siurala M. Cumulative 10-year risk of symptomatic duodenal and gastric ulcer in patients with or without chronic gastritis. Scand J Gastroenterol 1990;25:966-73.

33. Parsonnet J, Friedman GD, Vandersteen DP, et al. Helicobacter pylori infection and the risk of gastric carcinoma. N Engl J Med 1991;325:1127-31

34. Nomura A, Stemmermann GN, Chyou PH, Kato I, Perez-Perez GI, Blaser MJ. Helicobacter pylori infection and gastric carcinoma among Japanese Americans in Hawaii. N Engl J Med 1991;325:1132-6.

35. Hansson LE, Engstrand L, Nyren O, et al. Helicobacter pylori infection: independent risk indicator of gastric adenocarcinoma. Gastroenterology 1993;105:1098-103.

36. Huang J-Q, Sridhar S, Chen Y, Hunt RH. Meta-analysis of the relationship between Helicobacter pylori seropositivity and gastric cancer. Gastroenterology 1998;114:1169-79.

37. Fendrick AM, Chernew ME, Hirth RA, Bloom BS. Alternative management strategies for patients with suspected peptic ulcer disease. Ann Intern Med 1995;123:260-8.

38. Dohil R, Hassall E, Jevon G, Dimmick J. Gastritis and gastropathy of childhood. J Pediatr Gastroenterol Nutr 1999;29:378-94.

39. Delvin EE, Brazier JL, Deslandres C, Alvarez F, Russo P, Seidman E. Accuracy of the 13C-urea breath test in diagnosing Helicobacter pylori gastritis in pediatric patients. J Pediatr Gastroenterol Nutr 1999;28:59-62.

40. Harris A. Current regimens for treatment of Helicobacter pylori infection. Br Med Bull 1998;54:195-205.

41. Veldhuyzen Van Zanten SJO, Sherman PM, Hunt RH. Helicobacter pylori: new developments and treatments. Can Med Assoc J 1997;156:1565-74.

42. Israel DM, Hassall E. Omeprazole and other proton pump inhibitors: Pharmacology, efficacy, and safety, with special reference to use in children. J Pediatr Gastroenterol Nutr 1998;27:568-79.

\section{APPENDIX: PARTICIPANTS IN THE CANADIAN HELICOBACTER CONSENSUS CONFERENCE ON PEDIATRIC ISSUES}

The following people were leaders of the workshops and are co-authors of the present article: David Armstrong, Naoki Chiba, Ken Croitoru, Nigel Flook, Joanne Smith, Lesley Smith, Micheline Ste Marie and Barry Wershil.

The following people were participants in the Pediatric Symposium of the Canadian Consensus Conference on Helicobacter pylori infections and are co-authors of the present article: Alan Barkun (official representative of the Canadian Association of Gastroenterology), Charles Bernstein, Ted Bosworth, Hugh Chaun, Pierre Cloutier (official representative of Abbott Laboratories), Alan Cockeram, Steven Czinn, Andrew Day, James Deacon (official representative of the Canadian College of Family Practitioners), Collette Deslandres, Eric Drouin, Jean-Guy Emond, Gilles Fortin (official representative of Abbott Laboratories), Markus Goettke, Benjamin D Gold, Krishnasamy Govender, David Israel, Liisa Jaakkimainen, Kevan Jacobson, Nicola Jones, Monika Keelan, Agnes Klein (official representative of the Health Protection Branch), Kim Kouri, Joanne Langley (official representative of the Canadian Infectious Disease Society), Barbara Law (Canadian Paediatric Society), Raymond Lahaie, Rob Logan (official representative of Byk Canada Inc/Solvay Pharma Inc), Colin Macarthur, Bernard Marlow, Guiseppina Oderda, Colm O’Morain, Mohsin Rashid, Robert Riddell, Pierre Russo, Brent Scott, Andy Simor, Fionna Smaill, Paul Sinclair (official representative of Astra Pharma Inc), Wendy Smith (official representative of Astra Pharma Inc), John Snyder, Jean Spenard (official representative of Axcan Pharma Inc), Cathy Trieber and Scott Whittaker. 


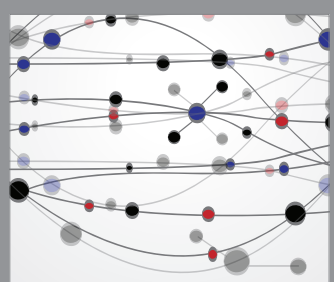

The Scientific World Journal
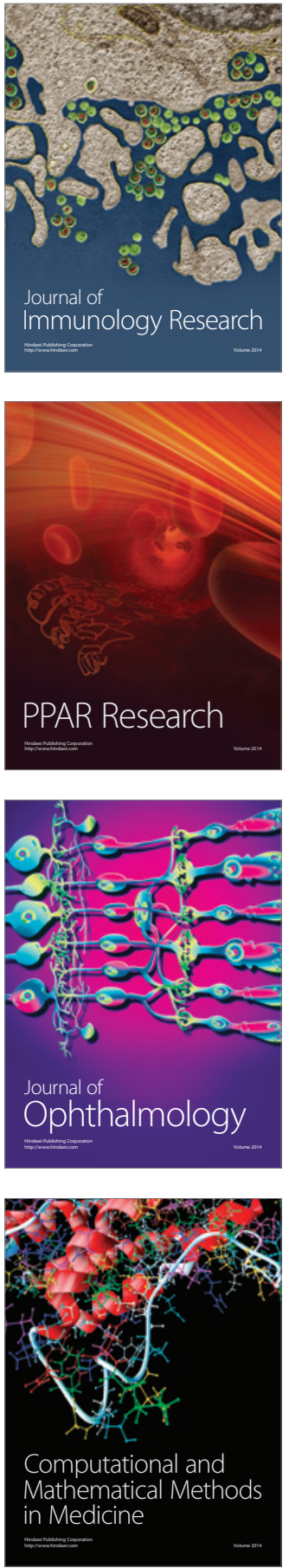

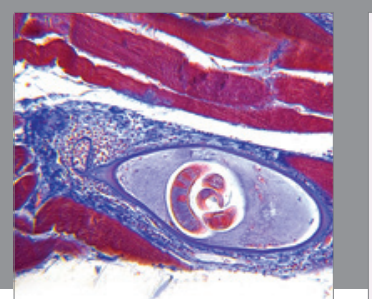

Gastroenterology Research and Practice

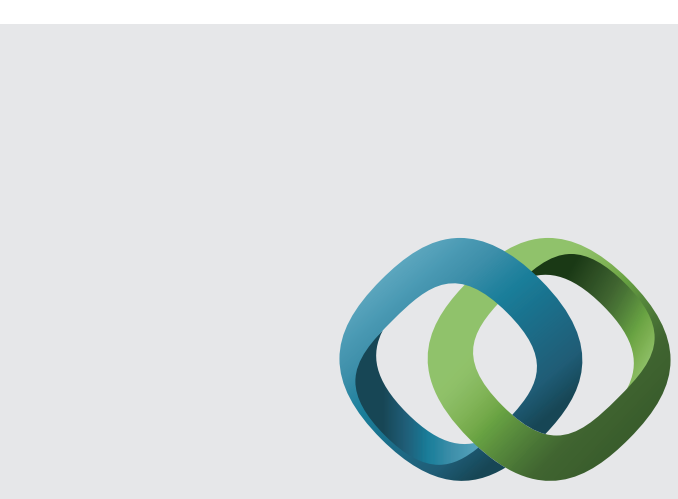

\section{Hindawi}

Submit your manuscripts at

http://www.hindawi.com
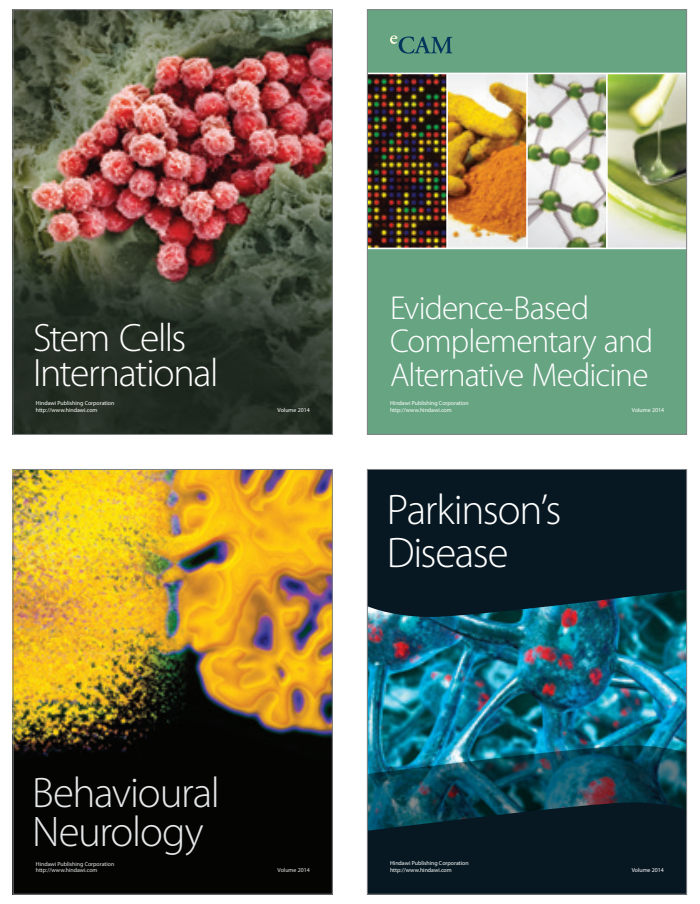
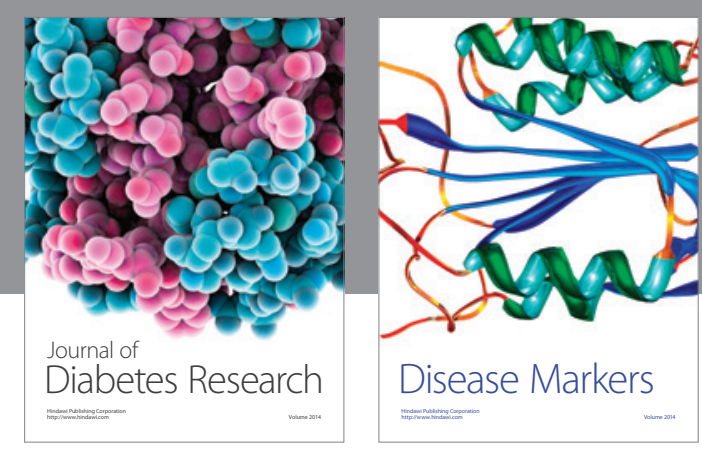

Disease Markers
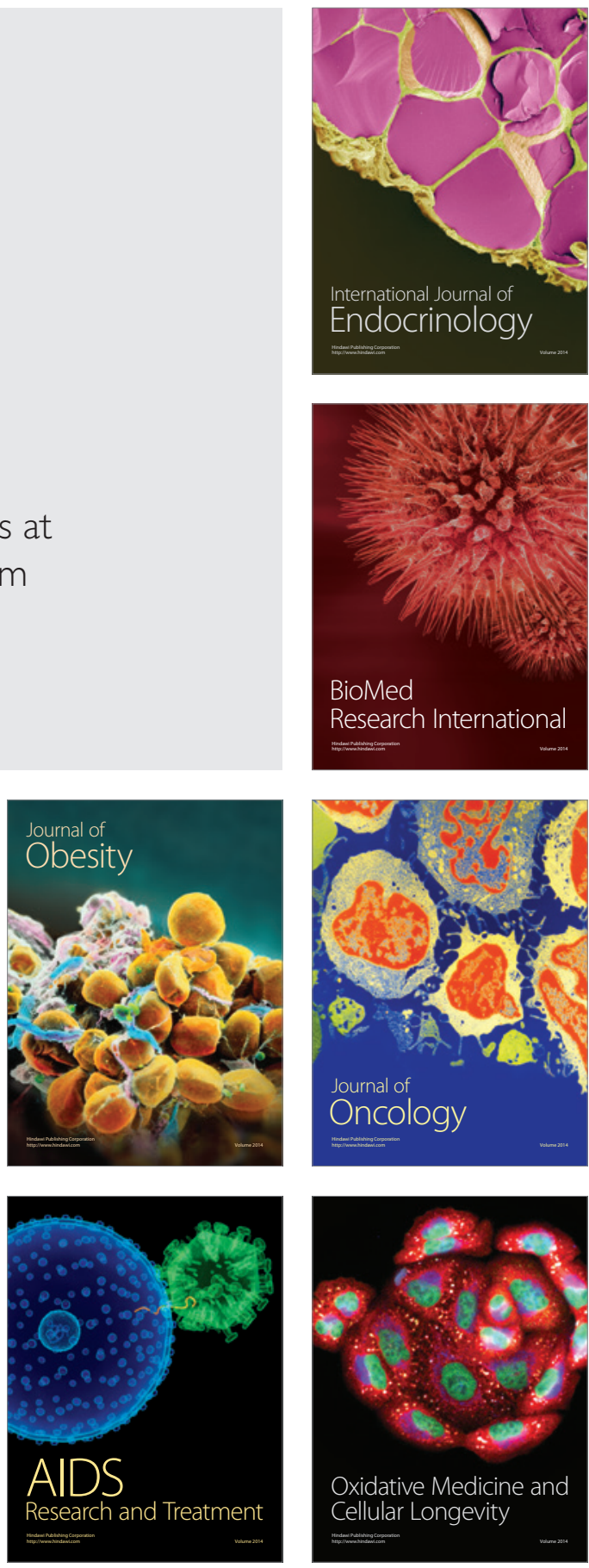